\title{
Two Dimensional and Color Doppler Ultrasound Scoring in Evaluation of Anterior Low Lying Placenta and its Adherence to Previous One Cesarean Section Scar inthe Third Trimester
}

\author{
Mohamed El-Saied Hassan Wasel ${ }^{1, *}$ M.B.B.CH, Mohamed Hesham Anwar ${ }^{1}$ MD, \\ Bassem Ragab Abdel-Aziz ${ }^{2}$ MD
}

\author{
* Corresponding Author: \\ Mohamed El-Saied Hassan Wasel \\ mohammed90wasel@gmail.com
}

Received for publication October 17, 2021; Accepted January 14, 2022; Published online January 14, 2022.

\section{Copyright The Authors published by Al-Azhar University, Faculty of Medicine, Cairo, Egypt. Users have the right to read, download, copy, distribute, print, search, or link to the full texts of articles under the following conditions: Creative Commons Attribution- Share Alike 4.0 International Public License (CC BY-SA 4.0).}

doi: 10.21608/aimj.2022.100728.1603

${ }^{I}$ Resident at Obstetrics and Gynecology Department, Faculty of Medicine, Al-Azhar University, Cairo, Egypt.

${ }^{2}$ Obstetrics and Gynecology Department, cairo fatemic hospital, Cairo, Egypt.

\begin{abstract}
Background: Placenta accreta is a potentially fatal obstetric disease which necessitates a multidisciplinary strategy to treatment. The occurrence of placenta accreta has grown, which appears to be correlated with the rising rate of cesarean deliveries. Women with myometrial damage from a prior cesarean birth, especially those with placenta previa anterior atop the uterine scar, are at the highest risk of placenta accreta. Aim of the study: : To assess the accuracy of each 2D \& CDF in diagnosing placenta accreta and to identify the prevalence, risk variables, and outcome of treatment of women with placenta accreta.

Patients and Methods: The study is a prospective cohort study that includes all cases diagnosed with placenta previa anterior plus one previous cesarean section who were admitted to Al Hussein and Sayed Galal University Hospital between January and December 2020. The study has been accepted by the obstetric department's ethical committee, and after proper counseling, all 107 women solicited for enrollment in the obstetric department and provided written informed consent.

Results: In prior cesarean delivery cases with placenta previa anterior, the occurrence of placenta accreta was $64 \%$.

Conclusion: Color Doppler imaging has high specificity and sensitivity for identifying placenta previa accreta, particularly anterior placenta accreta, since abnormal uteroplacental invasion may be detected with high confidence.

Keywords: Cesarean; accretaion; doppler; Ultrasound.
\end{abstract} Disclosure: The authors have no financial interest to declare in relation to the content of this
article. The Article Processing Charge was paid for by the authors.
Research Support: RCT approval numbers: NCT04656067 and PACTR202101794541918
Authorship: All authors have a substantial contribution to the article.

\section{INTRODUCTION}

Morbidly adherent placentas are characterized by a range of abnormalities, including placental myometrium invasion as well as invasion past the myometrium and muscle layers into adjacent structures. This condition has lately become increasingly common due to an increase in the frequency of cesarean deliveries, and it is classified into three classes depending on histopathology ${ }^{1}$.

Placenta accreta's exact pathogenesis is unknown. A number of theories have been offered, including decidua maldevelopment, excess trophoblastic invasion, or a mix of the two ${ }^{2}$. Deficient decidualization, abnormal maternal vascular remodeling, excess trophoblastic invasion, or combinations of these are thought to be the result of prior instrumentation ${ }^{3}$.

Placenta accreta is a serious pregnancy complication which can result in extensive and potentially life- threatening intrapartum and postpartum bleeding ${ }^{4}$. Placenta accreta has been the main reason for urgent hysterectomy due to severe uterine bleeding, which could necessitate extensive life-saving surgical treatments like hysterectomy and ligation of major pelvic vessels ${ }^{4}$.

As a result of placental invasion into nearby organs, repair of the urinary bladder or bowel might be required. In these drastic instances, massive transfusions of blood and blood products are the rule. Other complications include neonatal death, infection, fistula formation \& ureteral damage ${ }^{5}$.

Maternal morbidity and mortality have been documented in up to $60 \%$ and $7 \%$ of women with placenta accreta, respectively. Furthermore, the frequency of perinatal complications has grown, owing primarily to preterm delivery and fetuses that are undersized for gestational age 6 . 
A prior cesarean birth, especially when combined with a coexisting placenta previa, has been identified as a risk factor for placenta accreta. The risk of placenta accreta increases exponentially as the number of past cesarean births increases ${ }^{7}$. Other predisposing factors have been identified including: scarred uterus, multiple pregnancies, prior uterine operations, advanced mother age, and prior uterine curettage ${ }^{5,8}$.

The best time to diagnose placenta accreta is during the antenatal stage, using sonographic or magnetic resonance imaging methods. Much research has shown that ultrasonography can be used to make this diagnosis, especially at $<20$ weeks of pregnancy ${ }^{9}$. Regrettably, some instances of placenta accreta are detected during birth when the woman suffers from persistent vaginal hemorrhage or severe vaginal hemorrhage when the placenta is attempted to be removed, or merely a portion of the placenta may be removed ${ }^{10}$.

The study aimed to assess the accuracy of each 2D \& color Doppler flow in the placenta accrete diagnosis and to postulate a scoring system based on 2D and color Doppler flow criteria to predict placental invasion in women who have had at least one cesarean section in the $3^{\text {rd }}$ trimester.

\section{PATIENTS AND METHODS}

Type and Duration of the study: The study is a prospective cohort study that includes all cases diagnosed with placenta previa anterior plus one previous cesarean section who were admitted to $\mathrm{Al}$ Hussein and Sayed Galal University Hospital between January and December 2020. The study has been accepted by the obstetric department's ethical committee, and after proper counseling, all 107 women solicited for enrollment in the obstetric department and provided written informed consent.

Inclusion criteria include: Diagnosis: patients must have placenta previa anterior (anterior wall low lying). Gestational age: more than 30 weeks at the beginning of the research. Parity: patients must have one previous cesarean section.

Exclusion criteria: Patients with unscared uterus, or scared uterus other than cesarean section or more than one cesarean section. Patients who have a normally positioned placenta. Placenta previa posterior. Coagulopathy or other co-morbidity Diagnosis of placenta previa: Diagnostic criteria suspecte of placenta accreta

Ultrasound is the suggested initial step in diagnosing placenta previa accrete ${ }^{1)}$.

\begin{tabular}{|c|c|}
\hline US finding & Suggested standardized definition \\
\hline $\begin{array}{c}\text { 2D } \\
\text { grayscale }\end{array}$ & \\
\hline $\begin{array}{c}\text { Loss of } \\
\text { 'clear } \\
\text { zone' }\end{array}$ & $\begin{array}{c}\text { Hypoechoic plane loss or irregularity } \\
\text { in the myometrium beneath } \\
\text { theplacental bed ('clear zone') }\end{array}$ \\
\hline $\begin{array}{c}\text { The existence of multiple lacunae, } \\
\text { placental } \\
\text { lacunae }\end{array}$ & $\begin{array}{c}\text { some of which are huge and irregular } \\
\text { (Finberg Grade 3), and which } \\
\text { frequently include turbulent flow } \\
\text { evident on grayscale imaging }\end{array}$ \\
\hline Bladder & Bright bladder wall loss or \\
wall & interruption (hyperechoic band or 'line' \\
interruption & among uterine serosa and bladder \\
\hline
\end{tabular}

\begin{tabular}{|c|c|}
\hline $\begin{array}{c}\text { Myometrial } \\
\text { thinning }\end{array}$ & $\begin{array}{c}\text { Myomentrium thins overlying the } \\
\text { placenta to less than one millimeter or } \\
\text { undetectable }\end{array}$ \\
\hline $\begin{array}{c}\text { Placental } \\
\text { bulge }\end{array}$ & $\begin{array}{c}\text { The aberrant bulging of placental } \\
\text { tissues into an adjacent organ, usually } \\
\text { the bladder, causes the uterine serosa } \\
\text { to deviate from its anticipated plane. } \\
\text { The uterine serosa looks to be intact, } \\
\text { but the outline form is distorted }\end{array}$ \\
\hline $\begin{array}{c}\text { Focal } \\
\text { exophytic } \\
\text { mass }\end{array}$ & $\begin{array}{c}\text { Placental tissue is visible, breaking } \\
\text { through the uterine serosa and } \\
\text { expanding beyond it; it is most } \\
\text { commonly visible within a filled } \\
\text { urinary bladder }\end{array}$ \\
\hline
\end{tabular}

Table (1): Ultrasound criteria that diagnosis of morbidly adherent placenta.

Color Doppler ultrasound was recommended to assist in the placenta previa accreta diagnosis since it displays abnormal regions of hypervascularity with dilated blood vessels inside the placenta and uterine tissues ${ }^{12,1}$.

\begin{tabular}{|c|c|}
\hline $\begin{array}{l}\mathrm{CD} \\
\quad \text { finding }\end{array}$ & $\begin{array}{c}\text { Suggested standardized } \\
\text { definition }\end{array}$ \\
\hline \multicolumn{2}{|l|}{ color Doppler } \\
\hline $\begin{array}{c}\text { Uterovesical } \\
\text { hypervascularity }\end{array}$ & $\begin{array}{l}\text { A striking number of color } \\
\text { Doppler signals can be visible } \\
\text { across the myometrium and the } \\
\text { bladder's posterior wall; such a } \\
\text { signal most likely implies the } \\
\text { presence of many, tightly packed, } \\
\text { tortuous vessels within this area } \\
\text { (showing the aliasing artifact and } \\
\text { the multidirectional flow). }\end{array}$ \\
\hline $\begin{array}{c}\text { Subplacental } \\
\text { hypervascularity }\end{array}$ & $\begin{array}{l}\text { A striking number of color } \\
\text { Doppler signals are visible in the } \\
\text { placental bed; this signal most } \\
\text { likely implies the presence of } \\
\text { many, tightly packed, tortuous } \\
\text { vessels within this region } \\
\text { (showing the aliasing artifact and } \\
\text { the multidirectional flow). }\end{array}$ \\
\hline Bridging vessels & $\begin{array}{l}\text { Vessels that appear to stretch } \\
\text { from the placenta, through the } \\
\text { myometrium, and beyond the } \\
\text { serosa into the bladder or other } \\
\text { organs, frequently flowing } \\
\text { perpendicular to the myometrium }\end{array}$ \\
\hline $\begin{array}{c}\text { Placental } \\
\text { lacunae feeder } \\
\text { vessels }\end{array}$ & $\begin{array}{l}\text { High-velocity blood vessels that } \\
\text { go from the myometrium to the } \\
\text { placental lacunae, generating } \\
\text { disturbance upon entrance. }\end{array}$ \\
\hline
\end{tabular}

Table (2): Color Doppler criteria that diagnosis of morbidly adherent placenta

\section{Preoperative Preparation}

Preoperative procedures are designed to improve the outcome, decrease the risk of complications and make the surgical approach of placenta accreta as safe as possible, these preparations include: Complete laboratory tests: a full blood count, hepatic function tests, kidney function tests, and coagulation profile. If anemia is discovered, it must be corrected properly before delivery by blood transfusion if 
Hemoglobin level is below $9 \mathrm{gm} / \mathrm{dl}$ or the the fetus is more than 36 weeks gestation. Anemia may be corrected by parentral iron if Hemoglobin level is above $9 \mathrm{gm} / \mathrm{dl}$ or the fetus is less than 36weeks gestation. Proper counselling of the patient and her relatives about her case and possible complications as cesarean hysterectomy, bladder, intestinal injury up to death. Patients and her relatives must sign an informed consent form acknowledging that they are aware of risk and complications. The surgery will not proceed unless the consent form is signed. Preparing of cross matched blood of the same blood group at least two bags of blood and four units of fresh frozen plasma and must be available before surgery. Preparing of Intensive Care Unit (ICU) bed before the operation as some patients need ICU admission after delivery.

Outcomes:

Primary outcome criteria: During the 2nd cesarean section, placental accretion was discovered intraoperatively. (time frame): intra-operative during cesarean section

Secondary outcome criteria: Uterin conservation versus to cesarean hysterectomy. (time frame: intraoperative during cesarean section

Postpartum bleeding (time frame: from fetus birth to 24 hours following fetus birth) quantity of postpartum hemorrhage is > $1000 \mathrm{ml}$. Severe postpartum bleeding (time frame: from fetus birth to 24 hours following fetus birth) quantity of postpartum hemorrhage was $>1500 \mathrm{ml}$. Injury to the bladder (time frame: intra-operative) (during the cesarean birth time) Bladder injury as a result of the birth of the placenta or hemorrhage control.
Statistical analysis:

P-value: is the likelihood that the null hypothesis will be rejected (Ho). If the P-value is less than the chosen significance level then the null hypothesis (Ho) is rejected. The choice of significance level at which the Ho is rejected is arbitrary. Traditionally the $5,1.5 \& 0.1 \%(p<0.05,0.01,0.001)$ regions are used.

$\mathrm{P}$ : The probability/significance value: $\mathrm{P}$ value greater than 0.05 (NS) It's insignificant.* Significant at the 0.05 level when the $\mathrm{P}$ value is less than 0.05 . ** Significant at 0.01 level when $\mathrm{P}$ value is less than 0.01 .

Binary logistic regression: This technique has been utilized to predict the result of a categorical parameter depending on one or more predictive factors. Receiver operating characteristic (ROC curve) analysis has been done to determine the total predictivity of the parameter and the optimal cut-off value, as well as the specificity and sensitivity at this cut-off value.

Sensitivity, Specificity and Predictive value of Ultrasound and Doppler: Color Doppler imaging has high specificity and sensitivity for identifying placenta previa accreta, particularly anterior placenta accreta, since abnormal uteroplacental invasion might be observed with high confidence. Ultrasonography and Doppler were suggestive of morbid adherence in 38 instances $(95.2 \%)$ of patients approved by placenta accreta, with an accuracy of 96 $\%$, specificity of $97.3 \%$, sensitivity of $95.24 \%$, PPV of $98.36 \%$, and NPV of $92.31 \%$.

\section{RESULTS}

\begin{tabular}{|c|c|c|c|}
\hline & & \multicolumn{2}{|c|}{ Outcome (Intraoperative) } \\
\hline & & Positive $(n=67)$ & Negative $(n=40)$ \\
\hline \multicolumn{4}{|l|}{$\mathbf{U S}$} \\
\hline \multirow{2}{*}{ Loss of clear zone } & Positive & 62 & 5 \\
\hline & Negative & 5 & 35 \\
\hline \multirow{2}{*}{$\begin{array}{c}\text { Abnormal placental } \\
\text { lacunae }\end{array}$} & Positive & 64 & 3 \\
\hline & Negative & 3 & 37 \\
\hline \multirow{2}{*}{$\begin{array}{l}\text { Bladder wall } \\
\text { interruption }\end{array}$} & Positive & 22 & 0 \\
\hline & Negative & 45 & 40 \\
\hline \multirow[t]{2}{*}{ Myometrial thinning } & Positive & 62 & 4 \\
\hline & Negative & 5 & 36 \\
\hline \multirow[t]{2}{*}{ Placental bulge } & Positive & 62 & 5 \\
\hline & Negative & 5 & 35 \\
\hline \multirow[t]{2}{*}{ Focal exophytic } & Positive & 23 & 0 \\
\hline & Negative & 44 & 40 \\
\hline \multicolumn{4}{|l|}{ Color Doppler } \\
\hline \multirow{2}{*}{$\begin{array}{l}\text { Utero vesical hyper } \\
\text { vascularity }\end{array}$} & Positive & 64 & 13 \\
\hline & Negative & 3 & 27 \\
\hline \multirow{2}{*}{$\begin{array}{l}\text { Subplacental hyper } \\
\text { vascularity }\end{array}$} & Positive & 60 & 4 \\
\hline & Negative & 7 & 36 \\
\hline \multirow[t]{2}{*}{ Bridging vessels } & Positive & 64 & 13 \\
\hline & Negative & 3 & 27 \\
\hline \multirow{2}{*}{$\begin{array}{c}\text { Placental lacune feeder } \\
\text { vessels }\end{array}$} & Positive & 65 & 3 \\
\hline & Negative & 2 & 37 \\
\hline
\end{tabular}

Table 3: True positive \& negative and false positive \& negative of US and color Doppler compared to surgical intervention used as the "Gold Standard". 


\begin{tabular}{|c|c|c|c|c|c|}
\hline & Sensitivity & Specificity & Accuracy & $\begin{array}{c}\text { Positive } \\
\text { value }\end{array}$ & Negative value \\
\hline \multicolumn{6}{|l|}{ US } \\
\hline Loss of clear zone & $93 \%$ & $89 \%$ & $91 \%$ & $87 \%$ & $94 \%$ \\
\hline Abnormal placental lacunae & $97 \%$ & $93 \%$ & $95 \%$ & $91 \%$ & $98 \%$ \\
\hline Bladder wall interruption & $33 \%$ & $100 \%$ & $70 \%$ & $100 \%$ & $65 \%$ \\
\hline Myometrial thinning & $93 \%$ & $91 \%$ & $92 \%$ & $89 \%$ & $94 \%$ \\
\hline Placental bulge & $93 \%$ & $89 \%$ & $91 \%$ & $87 \%$ & $94 \%$ \\
\hline Focal exophytic & $34 \%$ & $100 \%$ & $70 \%$ & $100 \%$ & $65 \%$ \\
\hline \multicolumn{6}{|l|}{ Color Doppler } \\
\hline Utero vesical hyper vascularity & $96 \%$ & $68 \%$ & $82 \%$ & $61 \%$ & $98 \%$ \\
\hline Subplacental hyper vascularity & $90 \%$ & $90 \%$ & $90 \%$ & $86 \%$ & $93 \%$ \\
\hline Bridging vessels & $96 \%$ & $68 \%$ & $82 \%$ & $61 \%$ & $98 \%$ \\
\hline Placental lacune feeder vessels & $97 \%$ & $93 \%$ & $95 \%$ & $91 \%$ & $98 \%$ \\
\hline
\end{tabular}

Table 4: Sensitivity and specificity and Accuracy and Positive value and Negative value.

\begin{tabular}{cccccc}
\hline & B & Sig. & Odds ratio & \multicolumn{2}{c}{$95 \%$ CI for OR } \\
\cline { 5 - 6 } loss of clear zone & & & & Lower & Upper \\
Abnormal placental lacunae & 4.464 & $<0.001^{* *}$ & 4.3 & 1.175 & 9.622 \\
Bladder wall interruption & 5.573 & $<0.001^{* *}$ & 13.2 & 4.545 & 41.129 \\
Myometrial thinning & 2.948 & $0.005^{*}$ & 1.0 & 0.123 & 4.440 \\
Placental bulge & 4.715 & $<0.001^{* *}$ & 5.6 & 2.533 & 13.274 \\
\hline Focal exophytic & 4.464 & $<0.001^{* *}$ & 4.3 & 1.175 & 9.622 \\
\hline Utero vesical hyper vascularity & 3.015 & $0.004^{*}$ & 1.0 & 0.131 & 4.741 \\
\hline Subplacental hyper vascularity & 3.791 & $<0.001^{* *}$ & 2.2 & 0.584 & 5.044 \\
\hline Bridging vessels & 4.346 & $<0.001^{* *}$ & 3.9 & 1.900 & 8.459 \\
\hline Placental lacune feeder vessels & 3.791 & $<0.001^{* *}$ & 2.2 & 1.051 & 5.044 \\
\hline
\end{tabular}

Table (5): Multivariate regression analysis for prediction of placenta accreta using two dimensional and color Doppler ultrasound compared to surgical intervention used as the "Gold Standard".

\begin{tabular}{|c|c|c|c|c|}
\hline \multirow{2}{*}{$\begin{array}{l}\text { Total Score of finding through } \\
\text { US \& Color Doppler }\end{array}$} & \multicolumn{2}{|c|}{ Surgical Intervention } & \multicolumn{2}{|c|}{ Mann-Whitney test } \\
\hline & $\begin{array}{l}\text { Absent Outcome } \\
\qquad(\mathrm{n}=40)\end{array}$ & $\begin{array}{l}\text { Present Outcome } \\
\qquad(n=67)\end{array}$ & z-test & p-value \\
\hline Mean \pm SD & $5.78 \pm 4.68$ & $52.85 \pm 7.87$ & \multirow[t]{2}{*}{8.700} & \multirow[t]{2}{*}{$<0.001 * *$} \\
\hline Range & $0-39$ & $17-57$ & & \\
\hline
\end{tabular}

Using: Mann-Whitney z-test; **p-value $<0.001 \mathrm{HS}$

Table (6): Comparison between absent outcome and present outcome according to total score of finding through US \& Color Doppler.

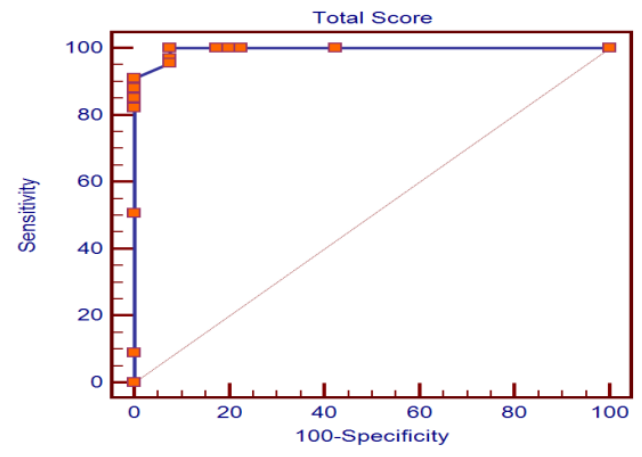

Fig. 1: The total Score of Finding through US \& Color Doppler was used to create a Receiver-operating characteristic (ROC) curve for predicting placental accreta.

\begin{tabular}{ccccccc}
\hline Cut-off & Sen. & Spe & PPV & NPV & Accuracy & p-value \\
\hline$\leq 37$ & $41.1 \%$ & $58.3 \%$ & $50.6 \%$ & $37.0 \%$ & $45.3 \%$ & $>0.05$ \\
$>37-<55$ & $51.7 \%$ & $71.1 \%$ & $62.8 \%$ & $44.0 \%$ & $59.7 \%$ & $<0.05^{*}$ \\
$\geq 55$ & $95.5 \%$ & $92.5 \%$ & $95.5 \%$ & $92.5 \%$ & $94.3 \%$ & $<0.001^{* *}$ \\
\hline
\end{tabular}

Table 7: The total Score of Finding through US \& Color Doppler was used to create a Receiver-operating characteristic (ROC) curve for predicting placental accreta.

The optimal cut off value of the total score was $\geq 55$, with sensitivity of $95.5 \%$, specificity of $92.5 \%$, PPV of $95.5 \%$, NPV of $92.5 \%$, and diagnostic accuracy of $94.3 \%$ using the (ROC) curve. 
Quantitative results were divided into quartile range of less than or equal to 25th percentile, 25-75th percentile and >75th percentile, accordingly, they are divided into 3 levels

The level of probability is divided into three levels; Less probability of placental accreta at cut-off score $(\leq 37)$; Mild to moderate probability of placental accreta at cut-off score $(>37-<55)$ and High probability of placental accreta at cut-off score $(\geq 55)$.

\section{DISCUSSION}

In our study, the prevalence of placenta accreta in instances of prior cesarean section with placenta previa anterior was $64 \%$. The sharp increase in prevalence was related to the rising prevalence of cesarean birth in recent years, and we selected more risk factors in the inclusion criteria of patients included in the study (previous cesarean, placenta previa anterior reaching the scar, and the cases collected from a referral center at $\mathrm{Al}$ Azhar University hospital).

The result of the study was as follow: Cesarean Hysterectomy performed in 5 cases of accretion and 2 cases with no accretion; injury to the bladder in 15 (14\%) patients; injury to the bowel in $1(0.9 \%)$ patient; intraoperative blood transfusion in $12(11 \%)$ patients; postoperative blood transfusion in $8(7 \%)$; and ICU admissions in 9 patients.

Howell et al. ${ }^{14}$ reported that Placenta accreta is much more common than placenta increta and percreta with the following incidences: placenta accreta $79 \%$; placenta increta $-14 \%$; and placenta percreta $7 \%$.

In females with placenta previa, Korb et al. ${ }^{15}$ discovered a relation between placenta accreta and the number of cesarean deliveries. Korb et al. ${ }^{15}$ reported that the frequency of placenta accreta rises with the number of cesarean births in women with placenta previa as follows: in females with placenta previa and no prior cesarean birth, 1 to $5 \%$, with one previous cesarean birth, 11 to $25 \%$, with two previous cesarean birth, 35 to $47 \%$, with 3 prior cesarean deliveries, $40 \%$, and with 4 or more prior cesarean deliveries, 50 to $67 \%$.

According to this study the 107 studied cases were divided according to the $2 \mathrm{D}$ and color Doppler finding (CDF) into two groups; the group B was 40 cases without sing of accretion, while the group A was 67 cases with sign of accretion. We found that, 38 women in the group B of 40 cases with sign of accretion, performed C.S only without hysterectomy, the group A 67 cases of sign of accretion during the operation 5 cases $(7 \%)$ were in need for cesarean hysterectomy to achieve complete homeostasis due to severe intrapartum hemorrhage resulted from failure of placental separation in 5 patients, while two case $(0.9 \%)$ sever uncontrolled atonic uterine bleeding after placental separation and uncontrolled bleeding from placental ped. All patients who performed C.H, underwent histopathological examination.

According to the presence or absence of myometrial invasion, the findings of histopathology affirmed the abnormal placenta diagnosis (accreta, increta, orpercreta) in $4 / 5$ cases with sing of accretion, so the 4 cases were true positive cases, while the remaining case were confirmed to have no pathology, so the one case was false positive case and she needed cesarean hysterectomy due to exaggerated bleeding from placental bed not controlled by ecbolics and Bakry ballon.

So this study demonstrated that there was a high significant relation between the definitive diagnosis of placenta accrete and the antenatal 2D \& color Doppler diagnosis of placenta accrete.

This study agrees with ACOG, as in our study, 2D \& color Doppler finding revealed placenta accreta in 67 patients, $7.46 \%$ of these patients underwent hysterectomy.

Other reports have shown that using color Doppler imaging to determine the depth of the placenta's invasion into the uterine myometrium or serosa might enhance the accuracy of the diagnosis of placenta accreta, particularly in instances in which the placenta is situated anteriorly ${ }^{16}$.

This study demonstrated that 2D \& color Doppler ultrasound in placenta accreta diagnosis had very high sensitivity $95.24 \%$, NPV $92.32 \%$, accuracy 96\%, specificity $97.30 \%$, and PPV $98.36 \%$.

Sonolucent area (A) criteria, it was preserved in $40 / 107$ cases, and absent in the remaining 67/107 cases, according to the definitive diagnosis of normal and abnormal placenta by pathological examination, it was found that A criterion had 62 true +ve cases, 5 false +ve cases, 35 true-ve cases, and 5 false -ve cases. So this criterion had high specificity $89.19 \%$, NPV $93.22 \%$, accuracy $88 \%$, PPV $84 \%$, and sensitivity $87.30 \%$.

Lacunae (D)criteria, was detected in 67/107 cases, and not detected in 40/107 cases, 64 cases with were true +ve cases, also had 24 true -ve cases, and 3 false -ve cases, and 3 false +ve cases, So lacunae had the highest sensitivity value $93.65 \%$ and the highest NPP $85.19 \%, 62.16 \%$ specificity, $80.82 \% \mathrm{PPV}$, and $82 \%$ accuracy.

Hypervascularity in uterine bladder interface $(\mathrm{H})$ criteria, it was detected in 77/107 cases, and not detected in 30/107 cases, 64 true +ve cases, 13 false +ve cases, 3 true -ve cases, and 27 false -ve cases. So (H) criterion had high specificity $94.59 \%$, NPV $51.47 \%$, accuracy $65 \%$, PPV $93.75 \%$, and sensitivity $47.62 \%$.

This study confirmed that lacunae (D) criterion was the most sensitive, with the highest NPV, than all other criteria of color Doppler ultrasound, and loss of plane of cleavage (A) criterion had the highest specificity and highest PPV, than all other criteria of color Doppler ultrasound, We also noted that hypervascularity in uterine bladder interface $(\mathrm{H})$ criterion had the lowest NPV of $51.47 \%$ than other criteria. 
This study confirmed that lacunae (D) criterion was the most sensitive, with the highest NPV, than all other criteria of color Doppler ultrasound, and loss of plane of cleavage (A) criterion had the highest specificity and highest PPV, than all other criteria of color Doppler ultrasound, We also noted that hypervascularity in uterine bladder interface $(\mathrm{H})$ criterion had the lowest NPV of $51.47 \%$ than other criteria

\section{CONCLUSION}

Color Doppler imaging has high sensitivity and specificity for diagnosing placenta previa accreta, particularly anterior placenta accreta, since abnormal uteroplacental invasion might be detected with high confidence. In this study ultrasound and color dopper of morbidly adherent placenta spectra shows: Less frequent criteria: Bladder wall interruption. Focal exophytic mass. Utero vesical hypervasculaity. Bridging vessels. More frequent criteria: Loss of clear zone. Myometerial thinning. Placental bulging. Sub-placental hypervascularity. Most frequent, specific and more accuracy criteria: Placental lacunae. Lacunae feeder vessel.

\section{REFERENCES}

1. Kaufman $\mathrm{C}$ and Tadros A. Endovascular interventions for the morbidly adherent placenta. Journal of Clinical Medicine. 2018; 7(5):92.

2. Garmi G, Salim R, Chulski A. Epidemiology, etiology, diagnosis and management of placenta accrete. 2011; 48:799-803.

3. Tantbirojn $\mathrm{P}$, Crum $\mathrm{CP}$ and Parast $\mathrm{MM}$ Pathophysiology of placenta creta: the role of decidua and extravillous trophoblast. Placenta. 2008; 29(7):639-45.

4. Wong HS, Cheung YK, Williams E. Antenatal ultrasound assessment of placental/myometrial involvement in morbidly adherent placenta. Australian and New Zealand Journal of Obstetrics and Gynaecology. 2012; 52(1):6772.

5. Jacques B and Helen DB. Placenta accreta and the risk of adverse maternal and neonatal outcomes. $J$. Perinat. Med. 2011; 41(2):141-9.

6. Hudon L, Belfort MA and Broome DR. Diagnosis and management of placenta percreta: a review. Obstet Gynecol Surv. 2013; 53:509-17.

7. Sivan E, Spira M, Achiron R, Rimon U, Golan G, Mazaki-Tovi S and Schiff E. "Prophylactic pelvic artery catheterization and embolization in women with placenta accreta: can it prevent cesarean hysterectomy?" Am J Perinatol. 2010; 27(6):455-61.

8. Miller DA, Chollet JA,Gielchinsky $\mathrm{J}$ and Goodwin TM. Clinical risk factors for placenta previa-placenta accreta. Am J Obstet Gynecol. 2010; 177:210-4.

9. Belfort MA, Publications Committee, Society for Maternal-Fetal Medicine. Placenta accreta. American journal of obstetrics and gynecology. 2010; 203(5):430-9.
10. Perez-Delboy A and Wright JD. Surgical management of placenta accreta: to leave or remove the placenta?. BJOG: An International Journal of Obstetrics \& Gynaecology. 2014; 121(2):163-70.

11. Doumouchtis S and Arulkumaran S. The morbidly adherent placenta: an overview of management options. Acta Obstet Gynecol Scand. 2010; 89(9):1126-33.

12. Levine D, Hulka CA, Ludmir J, Li W and Edelman RR. Placenta: evaluation with color Doppler US, power Doppler US, and MR imaging. Radiology. 2016; 205: 773-6.

13. Lerner JP, Deane $S$ and Timor-Tritsch IE. Characterization of placenta using transvaginal sonography and color Doppler imaging. Ultrasound Obstet Gynecol. 2013; 5: 198-201.

14. Howell KR and Powell TL. Effects of maternal obesity on placental function and fetal development. Reproduction (Cambridge, England). 2017; 153(3): 97.

15. Korb D, Goffinet F, Seco A, Chevret S, DeneuxTharaux C, EPIMOMS Study Group. Risk of severe maternal morbidity associated with cesarean delivery and the role of maternal age: a population-based propensity score analysis. CMAJ. 2019; 191(13): 352-360.

16. Calí G, Timor-Tritsch IE, Forlani F, PalaciosJaraquemada J, Monteagudo A, Agten AK, D'Antonio F. Value of first-trimester ultrasound in prediction of third-trimester sonographic stage of placenta accreta spectrum disorder and surgical outcome. Ultrasound in Obstetrics \& Gynecology. 2020; 55(4): 450-9. 